\title{
Morphological Assessment of Maxillary Sinus Septa Variations with Cone-Beam Computed Tomography in a Turkish Population
}

\author{
Nazan Kocak ${ }^{1}$ Esin Alpoz ${ }^{2}$ Hayal Boyacıoglu \\ ${ }^{1}$ Department of Oral and Maxillofacial Radiology, Faculty of \\ Dentistry, Yenisehir, Mersin University, Mersin, Turkey \\ 2Department of Oral and Maxillofacial Radiology, Faculty of \\ Dentistry, Ege University, Bornova, Izmir, Turkey \\ ${ }^{3}$ Department of Statistics, Faculty of Science, Ege University, \\ Bornova, Izmir, Turkey
}

Eur J Dent 2019;13:42-46

\author{
Address for correspondence Nazan Kocak, MDSc. Department of \\ Oral and Maxillofacial Radiology, Faculty of Dentistry, Yenisehir, \\ Mersin University, Mersin, 33110, Turkey \\ (e-mail: nazannkocak@gmail.com).
}

\author{
Abstract \\ Keywords \\ - cone-beam computed \\ tomography \\ - maxillary sinus \\ - septa \\ - sinus floor \\ augmentation
}

Objective The purpose of this study was to measure and classify sinus septa variables (prevalence, numbers, heights, locations, orientations, and morphology) and to determine the effects of age, gender, and dental status on the presence of septa and also to evaluate the effects of septa on pathological mucosal thickening.

Materials and Methods A total of 2,000 patients were analyzed through conebeam computed tomography (CBCT). The total of 500 maxillary sinuses were included in this study. The number of maxillary sinus septa was determined on axial sections of $\mathrm{CBCT}$ images. Their locations, orientations, and morphologies were determined on both the axial and sagittal sections, and their heights were determined only on the sagittal sections. The influence of age, gender, dental status, and pathological mucosal thickening on the presence of septa was statistically analyzed. Mann-Whitney U-test and descriptive statistics were used for statistical analysis.

Results The average height of the determined 287 septa was measured as $7.36 \mathrm{~mm}$. The highest rates of septa location, morphology, and orientation were found, respectively, in the middle region septa (57.49\%), completed septa (75.95\%), and transverse septa (93.37\%). The effect of dental status, age, and gender on the presence of septa was not statistically significant $(p>0.05)$.

Conclusion These high rates of findings support the importance of CBCT in the diagnosis of the variations of the maxillary sinus septa. Therefore, it is important to evaluate $C B C T$ images of the relevant region to increase the success of surgical interventions in the maxillary posterior region and to eliminate possible complications.

\section{Introduction}

The complex structure of posterior maxillary and maxillary sinus region problematizes implant rehabilitation of edentulous, most significantly the reduction in alveolar bone quality and quantity. ${ }^{1} \mathrm{~A}$ significant consequence of this is sinus pneumatization, which can ultimately lead to septa formation. ${ }^{2}$ These septa can then cause membrane perforation in sinus floor augmentation. ${ }^{3}$
Previous studies mostly focused on the existence of maxillary sinus septa in edentulous jaws. ${ }^{4,5}$ However, sinus septa have various anatomical manifestations. These are classified under headings such as septa location, morphology, and orientation. When septa are evaluated in terms of location, anterior septa exist between the first and second premolar region (sinus anterior wall) and the mesial of the first molar. Middle region septa exist between the mesial of the first molar and the distal of the second molar. Posterior 
septa are between the distal of the second molar and the posterior sinus wall. When septa are evaluated in terms of morphology, it is classified as completed septa or partial septa (uncompleted septa). When septa are evaluated in terms of septa orientation, different classifications are indicated. But in general, transverse septa extend in the mediolateral direction. Sagittal septa extend in the anteroposterior direction. Atypical septa extend outside the transverse and sagittal septa. ${ }^{1,3,4,6-11}$

The aim of this study was to measure and classify sinus septa variables and to determine age, gender, and dental status on the presence of septa and also to evaluate the effects of septa on pathological mucosal thickening.

\section{Materials and Methods}

Cone-beam computed tomography (CBCT) images of the maxillary posterior regions of 2,000 patients at the Department of Oral and Maxillofacial Radiology at the Ege University Faculty of Dentistry, dated between 2012 and 2015, were retrospectively evaluated in this study. A 14-7.1/6 No. Ege University Ethics Committee approval was received for this study, and informed consent was given by participants. CBCT images were analyzed on the axial, sagittal, and coronal planes.

Pediatric patients were excluded due to their ongoing maxillary sinus development. ${ }^{12}$ In CBCT sections, patients with $<6 \mathrm{~mm}$ distance from the deepest curvature of the maxillary sinus floor, patients with turbidity due to motions during tomography and artifacts due to various causes (beam hardening, noise, metal, and ring artifact), and insufficient image quality were excluded. Five hundred maxillary sinuses were ultimately included in this study.

Tomographic images were obtained using a Kodak 9000 3D CBCT device (Kodak Dental Systems, Carestream, Rochester, New York, United States) with total filtration $>2.5 \mathrm{~mm} \mathrm{Al}, 5 \mathrm{~cm} \times 3.7 \mathrm{~cm}$ imaging area, $76 \mu \mathrm{m}$ isotropic voxel size, and 14-bit contrast resolution. CBCT images were taken at $70 \mathrm{kVp}$ and maximum $10 \mathrm{~mA}$ as the standard. CBCT images were reviewed and all measurements performed by a single examiner (N.K.) using Kodak 3D Imaging Software 3.1.9 (Kodak Dental Systems, Carestream, Rochester, New York, United States).

The number of maxillary sinus septa was determined on the axial sections of CBCT images for each maxillary sinus. Their locations, orientations, and morphologies on the axial and sagittal sections and heights on the sagittal sections were determined.

Septa were identified as available in cases with $>4 \mathrm{~mm}$ septa height on the sagittal sections. This measurements were recorded for each septum ( - Fig. 1).

The maximum amount of maxillary sinus mucosal thickening was determined as the widest vertical distance from the thickest point to the sinus floor. A distance $>2 \mathrm{~mm}$ was considered pathological on the sagittal sections. The amount of maximum mucosal thickening was recorded for all

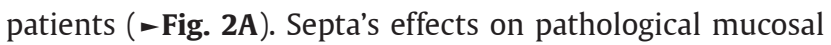
thickening were also assessed.

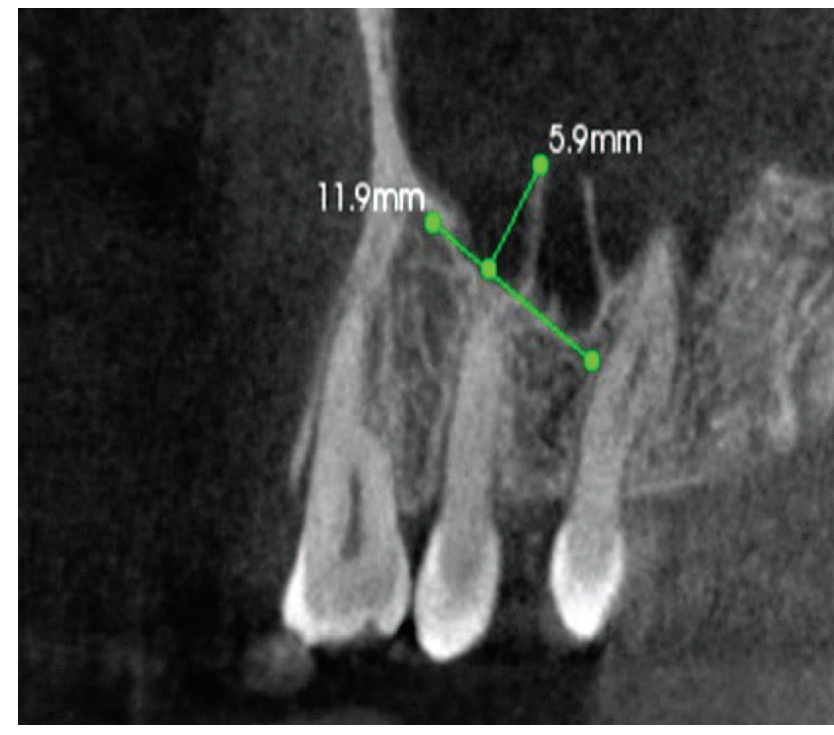

Fig. 1 Determining the height of septa on the sagittal section.

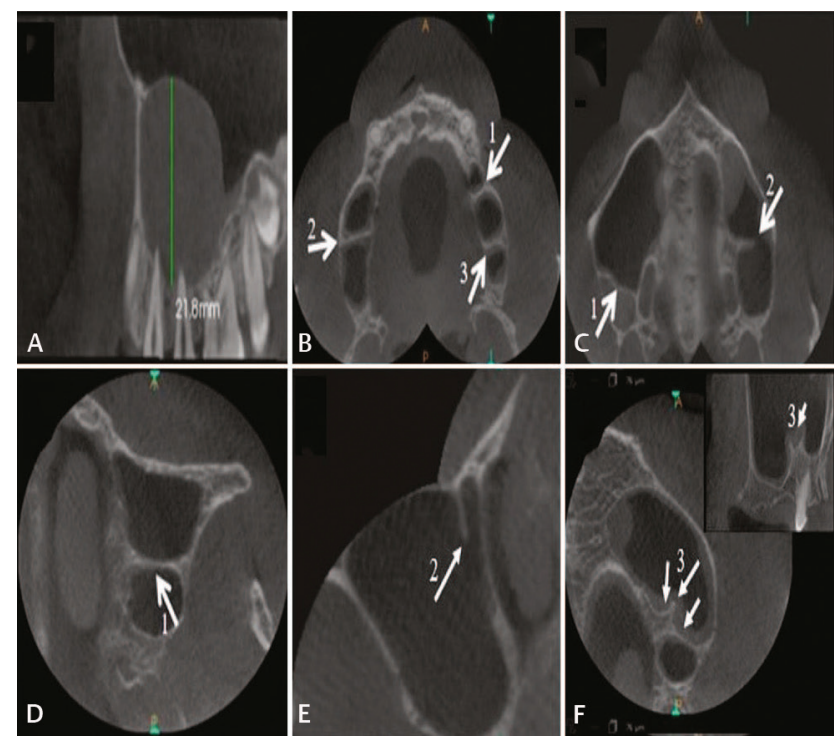

Fig. 2 (A) Measurement of mucosal thickening. (B) Determining septa location: (1) anterior septa, (2) middle septa, and (3) posterior septa. (C) Determining septa morphology: (1) completed septa and (2) partial septa. (D-F) Determining septa orientation: (1) transverse septa, (2) sagittal septa, and (3) atypical septa.

Septa location in the maxillary sinus was determined on the axial and sagittal sections in CBCT and classified as anterior, middle region, or posterior ( - Fig. 2B). The septa morphology of the maxillary sinus on the same sections was classified as completed septa or partial septa ( - Fig. 2C). In addition to, maxillary sinus septa orientation was classified on the axial section as transverse septa, sagittal septa, and atypical septa (-Fig. 2D-F).

Descriptive statistics were used in the distribution of septa location, orientation, and morphology; the chi-squared test was used for the relationship of age, gender, and dental status with septa; and the MannWhitney U-test was used to evaluate septa's effects on maximum mucosal thickening. $p$-Value $<0.05$ was considered statistically significant. 


\section{Results}

The total 376 patients (average age $43.14 \pm 17.6$ ) were aged between 18 and 82 years. Five hundred maxillary sinuses were included in this study. Of these, 244 (48.6\%) were female and 256 (51.2\%) were male. The presence of 287 maxillary sinus septa was determined. There was no septa in the most of patients (52.4\%) ( - Fig. 3). The effect of dental status $(p=0.225)$, gender $(p=0.643)$, and age $(p=0.063)$ on the presence of septa was found to be insignificant by chi-squared tests.

When the height of the maxillary sinus septa was evaluated, it was measured as $7.36 \mathrm{~mm}$ on average (minimum $3.90 \mathrm{~mm}$ and maximum $21.67 \mathrm{~mm}$ ). Mucosal thickening was $1.04 \mathrm{~mm}$ on average. The presence of maximum mucosal thickness in cases with septa $(6.3 \pm 6.2 \mathrm{~mm})$ and the presence of maximum mucosal thickness in cases without septa $(6.1 \pm 5.9 \mathrm{~mm})$ were calculated using mean value and standard deviation. When the effect of septa on pathological mucosal thickening was evaluated, it was found that the highest distribution value among the groups was pathological mucosal thickening in the absence of septa in $34.8 \%$ ( - Fig. 4). This reveals that the

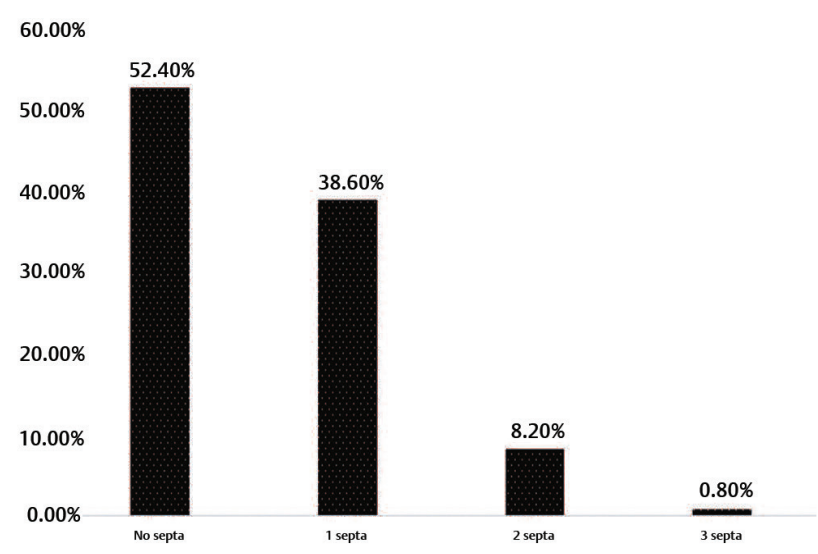

Fig. 3 Distribution of number of septa observed in each maxillary sinus.

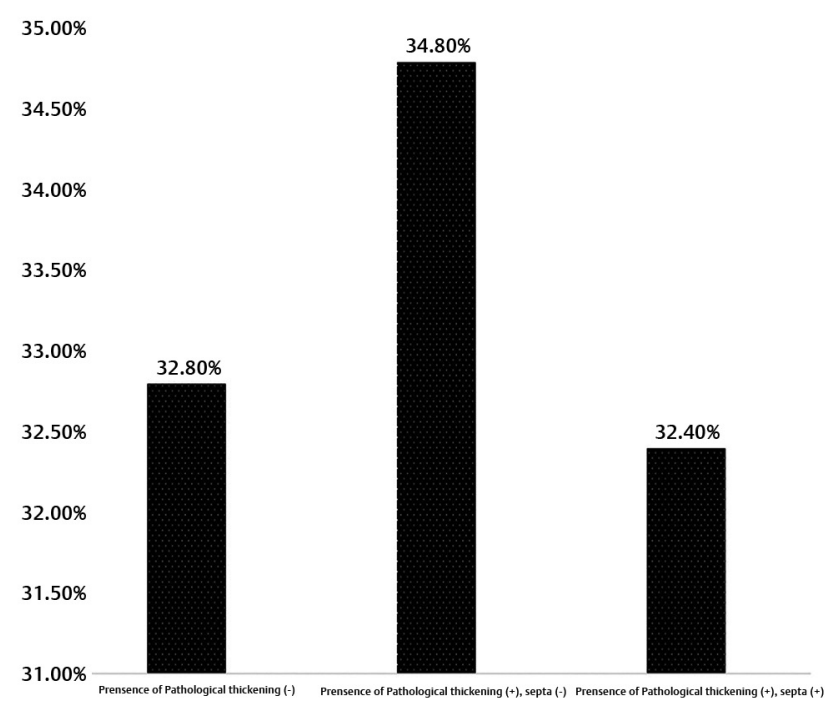

Fig. 4 Distribution of the effects of septa presence on pathological mucosal thickening. effect of the presence of septa on the amount of the maximum mucosal thickening was statistically insignificant $(p=0.863)$.

When the distributions of septa morphology, location, and orientation were evaluated, the highest values were $75.95 \%$ completed septa, $57.49 \%$ middle region septa, and 93.37\% transverse septa, respectively ( - Table $\mathbf{1}$ ).

\section{Discussion}

Sinus lift operations may cause sinus membrane perforations due to anatomical variations and septa. Radiologic evaluation of septa size and location prevents complications during and after sinus lifts. ${ }^{10}$

Septa prevalence in maxillary sinuses in this study was $47.6 \%$. In previous studies, researchers determined this ratio between 13.7 and $58 \% \%^{3,6,8,11,13-15}$ Studies differ depending on radiographic methods, septa identification criteria, and samples. The higher prevalence in this study was based on the thin slice interval of CBCT images $(0.076 \mu \mathrm{m})$. While some researchers consider heights over $2.5 \mathrm{~mm}$ as septa, ${ }^{6,16,17} \mathrm{Jang}$ et $\mathrm{al}^{6}$ identify the bone walls of $4 \mathrm{~mm}$ and above as septa. In our study, the height which was determined by Jang et $\mathrm{al}^{6}$ was taken as a reference.

Various radiographic methods, such as panoramic radiography, ${ }^{14} \mathrm{CT}^{8,9,911,14}$ and $\mathrm{CBCT}^{3,6,7,13,18}$ were used to assess maxillary sinus septa. Here, CBCT was preferred because it facilitates detailed assessment of maxillary sinus anatomy and decreases surgical risks. ${ }^{19}$

Here, average septa height was $7.36 \mathrm{~mm}$. In the literature, average septa height is reported as $3.54 \mathrm{~mm}$ in panoramic radiography, ${ }^{14} 6.6 \mathrm{~mm}$ in tomographic sections, ${ }^{4,11}$ and $4.62 \mathrm{~mm}$ in CBCT images. ${ }^{3,6,11,14,18}$ It has been determined that this finding obtained from our study is quite high compared with the values stated in the literature. This situation is explained by the high resolution of the CBCT device used in our study. Advanced imaging techniques with high resolutions, such as CBCT, increase anatomical structures' detectability.

As surgical operations involving maxillary sinus segments gain prevalence, radiological evaluation determining size, shape, and location of septa gains importance. In studies evaluating septa locations, $3,6,8,11$ septa were averagely observed to be $28.1 \%$ in the anterior region, $52.55 \%$ in the middle region, and $25.19 \%$ in the posterior region. Researchers disagree on whether middle region septa, ${ }^{18}$

Table 1 Distribution of findings of septa location, morphology, and orientation

\begin{tabular}{|l|l|l|}
\hline Septa location & $\begin{array}{l}\text { Septa } \\
\text { morphology }\end{array}$ & Septa orientation \\
\hline $\begin{array}{l}23.7 \% \text { anterior } \\
\text { septa }\end{array}$ & $\begin{array}{l}75.95 \% \\
\text { completed septa }\end{array}$ & $\begin{array}{l}\text { 93.37\% transverse } \\
\text { septa }\end{array}$ \\
\hline $\begin{array}{l}57.49 \% \text { middle } \\
\text { septa }\end{array}$ & $\begin{array}{l}24.05 \% \text { partial } \\
\text { septa }\end{array}$ & $\begin{array}{l}3.83 \% \text { sagittal } \\
\text { septa }\end{array}$ \\
\hline $\begin{array}{l}18.81 \% \text { posterior } \\
\text { septa }\end{array}$ & & $\begin{array}{l}2.80 \% \text { atypical } \\
\text { septa }\end{array}$ \\
\hline
\end{tabular}


anterior septa, ${ }^{6}$ or posterior septa ${ }^{15}$ are more prevalent. However, middle region septa were found more frequently in our study (57.49\%). Inconsistent findings can be explained by different data collection methods and nonstandardized location determination among researchers. Further studies are needed to settle these disagreements, as septa location is important in sinus drainage interruption and pathology formation.

Here, morphologically completed septa $(75.95 \%)$ were found to be more prevalent than partial septa (24.05\%). Krennmair et a $^{20}$ determined completed septa at $95 \%$ and partial septa at $5 \%$. Ella et $\mathrm{al}^{9}$ specified that partial septa accounted for $39 \%$ of all septa. The clinical significance of partial and completed septa depends on their location, height, and the type of surgery performed.

When our findings were evaluated in terms of septa orientation, transverse septa (93.37\%) were found to be more prevalent than sagittal (3.83\%) or atypical septa (2.80\%). Although researchers' orientation classification shows difference, septa orientation should be determined before maxillary sinus surgery. ${ }^{1,6}$ In a study evaluating the relationship between septa orientation and sinus lift complications, it has been reported that membrane perforation occurs mostly in the presence of transverse septa and severity of this perforation depends on septa size and height. ${ }^{1}$ In the light of this information, transverse septa cases should be approached carefully.

Different findings of the effects of dental status on septa $^{3,8,14}$ result from differences in radiographic methods and patients' dental statuses, ages, genders, and races. For example, two similar studies' findings differ: Ozeç et al ${ }^{14}$ argue that septa prevalence is more frequent in edentulous individuals, while Orhan et $\mathrm{al}^{3}$ emphasize increased prevalence in partially edentulous individuals.

In this study, it was determined that septa presence has no statistically significant effect on mucosal thickening $(p=0.863)$. Cakur et $\mathrm{al}^{13}$ identified an inverse relationship between mucosal thickening and septa presence. Rancitelli et $\mathrm{al}^{18}$ reported that average mucosal thickness increased around septa.

Our study has significant limitations-such as being a retrospective study, single-observer measurements, and uneven sample distribution of dental status. On the other hand, there are no versatile retrospective studies analyzing the septum's characteristic features and conditions associated with septa presence.

Within the limitations of this study, the following conclusions were made: (1) In our study, the use of highresolution $\mathrm{CBCT}$ is thought to be a factor in the findings of high septa prevalence (47.6\%) and high septa height $(7.36 \mathrm{~mm})$. (2) This study found that the effects of dental status, gender, and age on septa presence were negligible and that septa presence does not affect maximum mucosal thickening. In addition to these findings, it is thought that during surgical planning, determining the number, height, morphology, orientation, and localization of the maxillary, sinus septa will be effective in preventing complications.

\section{Financial Support and Sponsorship}

Nil.

\section{Conflicts of Interest}

None declared.

\section{Acknowledgment}

We sincerely thank patients of Ege University, Faculty of Dentistry, who voluntarily participated in our study.

\section{References}

1 Irinakis T, Dabuleanu V, Aldahlawi S. Complications during maxillary sinus augmentation associated with interfering septa: a new classification of septa. Open Dent J 2017;11:140-150

2 Vinter I, Krmpotić-Nemanić J, Hat J, Jalsovec D. [Does the alveolar process of the maxilla always disappear after tooth loss?] Laryngorhinootologie 1993;72(12):605-607

3 Orhan K, Kusakci Seker B, Aksoy S, Bayindir H, Berberoğlu A, Seker E. Cone beam CT evaluation of maxillary sinus septa prevalence, height, location and morphology in children and an adult population. Med Princ Pract 2013;22(1):47-53

4 Krennmair G, Ulm C, Lugmayr H. Maxillary sinus septa: incidence, morphology and clinical implications. J Craniomaxillofac Surg 1997;25(5):261-265

5 Shibli JA, Faveri M, Ferrari DS, et al. Prevalence of maxillary sinus septa in 1024 subjects with edentulous upper jaws: a retrospective study. J Oral Implantol 2007;33(5):293-296

6 Jang SY, Chung K, Jung S, Park HJ, Oh HK, Kook MS. Comparative study of the sinus septa between dentulous and edentulous patients by cone beam computed tomography. Implant Dent 2014;23(4):477-481

7 Hadchiti W, Nasseh I, Hayek E, Mora F, Bouchard P. Prevalence, location and orientation of maxillary sinus septa. Ann Oral Maxillofac Surg 2014;2:9

8 Shen EC, Fu E, Chiu TJ, Chang V, Chiang CY, Tu HP. Prevalence and location of maxillary sinus septa in the Taiwanese population and relationship to the absence of molars. Clin Oral Implants Res 2012;23(6):741-745

9 Ella B, Noble RdaC, Lauverjat Y, et al. Septa within the sinus: effect on elevation of the sinus floor. Br J Oral Maxillofac Surg 2008;46(6):464-467

10 Sakhdari S, Panjnoush M, Eyvazlou A, Niktash A. Determination of the prevalence, height, and location of the maxillary sinus septa using cone beam computed tomography. Implant Dent 2016;25(3):335-340

11 Faramarzie M, Babaloo AR, Oskouei SG. Prevalence, height, and location of antral septa in Iranian patients undergoing maxillary sinus lift. JIPD 2009;1:43-47

12 Teng M, Cheng Q Liao J, Zhang X, Mo A, Liang X. Sinus width analysis and new classification with clinical implications for augmentation. Clin Implant Dent Relat Res 2016;18(1):89-96

13 Cakur B, Sümbüllü MA, Durna D. Relationship among Schneiderian membrane, Underwood's septa, and the maxillary sinus inferior border. Clin Implant Dent Relat Res 2013;15(1):83-87

14 Ozeç I, Kılıç E, Müderris S. Maxillary sinus septa: Evaluation with computed tomography and Panoramic radiography. Cumhuriyet Dental Journal 2008;11:82-86

15 Underwood AS. An inquiry into the anatomy and pathology of the maxillary sinus. J Anat Physiol 1910;44(Pt 4):354-369

16 Ulm CW, Solar P, Krennmair G, Matejka M, Watzek G. Incidence and suggested surgical management of septa in sinus-lift procedures. Int J Oral Maxillofac Implants 1995;10(4):462-465 
17 Velásquez-Plata D, Hovey LR, Peach CC, Alder ME. Maxillary sinus septa: a 3-dimensional computerized tomographic scan analysis. Int J Oral Maxillofac Implants 2002;17(6):854-860

18 Rancitelli D, Borgonovo $\mathrm{AE}$, Cicciù $\mathrm{M}$, et al. Maxillary sinus septa and anatomic correlation with the Schneiderian membrane. J Craniofac Surg 2015;26(4):1394-1398
19 Almog DM, Romano PR. CT-based dental imaging for implant planning and surgical guidance. N Y State Dent J 2007;73(1):51-53

20 Krennmair G, Ulm CW, Lugmayr H, Solar P. The incidence, location, and height of maxillary sinus septa in the edentulous and dentate maxilla. J Oral Maxillofac Surg 1999;57(6):667-671, discussion 671-672 